\title{
WYTWÓRCZOŚĆ LUDÓW PIERWOTNYCH W ŚWIETLE PRAGMATYCZNYCH KONCEPCJI SZTUKI
}

\author{
THE MANUFACTURE OF THE PRIMORDIAL TRIBES \\ IN THE CASE OF PRAGMATIC CONCEPTS OF THE ART
}

\author{
Andrzej P. Kowalski \\ orcid.org/0000-0003-2009-2689 \\ Instytut Archeologii i Etnologii, Uniwersytet Gdański \\ ul. Bielańska 5, 80-894 Gdańsk \\ a.p.kowalski@wp.pl
}

\begin{abstract}
The article is devoted to the function of the primordial art in the pragmatic concept. The pragmatism ennobles the unprofessional forms of artistic activity. It makes it following the deconstruction of the modern definitions of the art. It presents the aesthetic values of primordial art. In the article, there are included its characteristics made by J. Dewey and É. Durkheim who used the first ethnographic data. Their description of the Australian autochthones shows its social contexts. It served to intensify certain emotions. It was the art of movement and dynamics. It harmonized with the whole experience of the life of the primordial hunters. It did not operate on symbols as understand these days. The pragmatic approach makes the aesthetic notion of the manufacture more important than its cognitive aspects. It does not eliminate the dilemmas of the character of the art in the cultures beyond Europe. It does not give archaeologists any simple tool to interpret the prehistoric facts.
\end{abstract}

KEY WORDS: primordial art, pragmatism, John Dewey, primordial thinking, art as experience

Zagadnienie istoty sztuki ludów pierwotnych powoli staje się zagadnieniem z zakresu historii idei estetycznych, ponieważ, jak można przypuszczać, nie budzi już żywego zainteresowania np. wśród archeologów. Również na gruncie refleksji teoretycznej poświęconej filozofii sztuki pytanie o charakter sztuki pozaeuropejskiej czy prehistorycznej jest stawiane rzadziej. Nie oznacza to, że kwestia ta jest zupełnie pomijana w dyskusjach antropologicznych. Dla antropologów i filozofów kultury problematyka przeżyć estetycznych ludów pierwotnych, estetycznej waloryzacji przedmiotów powstałych w kulturach pozaeuropejskich odzyskuje ważność, ale jako 
argument $\mathrm{w}$ dyskursie postkolonialnym. Odchodzenie od podejmowania prób esencjonalnych określeń sztuki, uniwersalnie obowiązujących i wobec tego dotyczących wytwórczości prehistorycznej lub pozaeuropejskiej, wynikało z postmodernistycznej krytyki nowożytnych kategorii w zakresie estetyki i sztuki. Dotychczasowe wysiłki związane z projektami uniwersalizującymi pojęcie sztuki odczytano bowiem jako element intelektualnego kolonialnego procesu deprecjonowania tradycji pozaeuropejskich.

Przypomnijmy, że sztuka rozumiana w kategoriach wybitnie estetycznych pojawia się na kartach filozofii dopiero w XVIII wieku. W dobie narastającego triumfu racjonalności oświeceniowej przeżycia estetyczne i sfera doświadczeń zmysłowych domagały się opisu za pomocą specyficznej logiki. Alexander Baumgarten w swoich Meditationes z 1735 roku wprowadza termin cogitatio sensitiva, a potem w dziele Aesthetica formułuje zasady logiki dyscyplin wykorzystujących dane, które płyną z doznania zmysłowego i przydziela specjalne miejsce działaniom artystycznym (Żelazny, 1994). Sztuka zatem definiowana była jako działalność obliczona na kreowanie obiektów estetycznie waloryzowanych, służąca niemal wyłącznie upodobaniu.

Utrwalone w tradycji europejskiej nowoczesności postrzeganie sztuki w kategoriach autonomicznej sfery aktualizacji wartości estetycznych od dawna natrafiało na sprzeciw badaczy zajmujących się przejawami sztuki w społeczeństwach pierwotnych (Lewis, 1961). Towarzyszył temu opór wobec wykorzystywania teorii sztuki, nade wszystko jako sztuki pięknej, do porównywania jej dokonań z efektami wytwórczości, które notowano wśród pierwotnych plemion lub na etnograficznych czy archeologicznych ekspozycjach muzealnych. Wynik tych porównań wypadał zazwyczaj na niekorzyść ludów pierwotnych. Wrażenie tej negatywnej oceny potęgowały z jednej strony opinie na temat ograniczonych zdolności artystycznych twórców z plemion pierwotnych, a z drugiej strony definicyjne wykluczenie ich osiągnięć poza rejon sztuki. Niewiele pomagają tu próby wysubtelnienia rozróżnień proponowanych przez niektórych antropologów, żeby o sztuce plemiennej mówić „autentyczna”, a więc pozbawiona pretensji do świadomego kreowania fantastycznych ontologii czy iluzorycznych, aczkolwiek pięknych światów przedstawionych. Podobnie z pojęciem „sztuki zamierzonej” (art by intention), funkcjonującej w kontekście uświadamianej wyjątkowości jej dzieł, oraz z pojęciem, ,sztuki przez przypisanie” (art by appropriation). W drugim przypadku asygnowanie sztuki ma miejsce wtedy, gdy z jednej strony podmioty godzą się na uznanie pewnych dzieł jako tworów artystycznych, a z drugiej, gdy badacz dokonujący ich oceny z zewnątrz samowolnie nadaje im określoną kwalifikację estetyczną (Errington, 1994, s. 203-204).

Konsekwencje długotrwałego rozróżnienia na elitarną sztukę, uprawianą tylko w Europie w łonie wydzielonej kultury artystycznej z jej estetycznie wysoko wartościowanymi dziełami, i na rękodzieło, a więc spontaniczne ekspresje rytualne pozbawione intencji estetycznej, ujawniły się także w ocenie ogólnych predyspozycji duchowych ludzi pierwotnych. Społeczności pierwotne traktowano jak uwikłane w zadanie reprodukcji podstaw wiedzionego przez nie życia. Dlatego, jak uważano, ich nastawienie do świata i wyrosła z tego mentalność nie premiowały pielęgnowania 
tradycji funkcjonalnie niezależnych, tak jak niektóre zajęcia Europejczyków służące tylko i wyłącznie zaspokajaniu potrzeby ujmowania piękna, potrzeby poszerzania wiedzy itp.

Reakcją na takie dychotomie była etyczna rehabilitacja ludzi pierwotnych. Starano się wynagrodzić im krzywdy wywołane przez eurocentrycznie nacechowane interpretacje i wykazać, że w ich kulturze można odnaleźć ogólnoludzkie skarby duszy. Stąd w odpowiedzi na postponujące ludzi pierwotnych opinie o ich prelogicznym myśleniu, ich magiczności i nadmiernej emocjonalności, o braku wysublimowanych koncepcji i idei doświadczanych zjawisk zaczęto przywracać im godność podmiotu operującego myśleniem symboliczno-dyskursywnym i legitymującego się uwrażliwieniem na piękno (Torgovnick, 1989; Płonka, 2012, s. 74-89).

Nie można uniknąć pewnych paradoksów w sytuacji, gdy zderzają się stereotypy nieokrzesanego i szlachetnego dzikusa. Jeśli sztuka, zgodnie z modernistycznym jej ujęciem, podporządkowana jest wyłącznie zadaniom estetycznym, a więc ocenie wypływającej z doświadczenia zmysłowego, to dlaczego odmawiano idei piękna ludom podobno zatopionym w zmysłowości? Ich rzekomo ograniczony intelekt - otwierający szerokie pole recepcji danych sensualnych - mógłby właśnie sprzyjać doznaniom jakości estetycznie doniosłych, których uznanie obywa się, według Kanta, bez pośrednictwa pojęć. Tradycja modernistyczna wydobyła estetykę jako filozofię „niższych” form poznania, ale zarazem uczyniła z niej narzędzie konceptualizacji sztuk pięknych i dlatego odmówiła ludom pierwotnym posiadanie rzeczywistego „zmysłu piękna”. Inna sprzeczność widoczna jest w strategiach rehabilitacyjnych realizowanych w ramach dyskursów dekolonizacyjnych. Skoro eurocentryczne klasyfikacje pozbawiały rzeczywistość kulturową ludów pierwotnych obecności sztuki, to jakoś należało ten błąd naprawić. $\mathrm{Z}$ tego powodu w badaniach antropologicznych skoncentrowano się na zrekompensowaniu dotychczasowych negatywnych interpretacji. Dobrym przykładem jest artykuł Harolda K. Schneidera na temat afrykańskiego ludu Pakot. Według tego antropologa kenijscy pasterze dysponują niemal identyczną jak Europejczycy kategoryzacją obiektów: niektóre uważają za codzienne, użytkowe, niezbędne do przeżycia, inne za takie, które służą estetycznej przyjemności. Przedmioty klasy paching są ładne, miło jest na nie patrzeć, natomiast rzeczy z kategorii karam są tylko „dobre”. Do przedmiotów ładnych należą naszyjniki, muszle, miedziane bransolety i barwione powierzchnie. Przedmioty użyteczne pozbawione odpowiednich walorów nie mogą uchodzić za piękne. Lud Pakot ma więc nie tylko świadomość istnienia pięknych przedmiotów, ale swoje rozróżnienia na obiekty estetycznie waloryzowane i powszednie zawiera w rodzimym słownictwie (Schneider, 1971, s. 55-61). W kulturze Aborygenów australijskich, przywoływanych często w charakterze ostańców prehistorii, w wyniku zabiegów zadośćuczynienia dokonano introdukcji kategorii sztuki według kanonów europejskich. Wszystko po to, aby lokalne wytwory mogły stać się cenionym i poszukiwanym towarem dla miłośników pierwotnego kunsztu i dla placówek muzealnych. Aborygeni przyswoili sobie europejskie pojęcie sztuki pięknej, zaczęli nim określać własne wyroby z powodów czysto merkantylnych. Pojęcie sztuki pięknej 
okazało się zatem intratną kategorią w nowej odsłonie pojęciowego kolonizowania australijskich dóbr kultury (Morphy, 1996).

Powstaje jednak pytanie, z jakiego powodu poszukujemy ludów pierwotnych dysponujących w zasadzie europejską aksjologią dotyczącą estetyki i sztuki? Przecież przywracanie pozaeuropejskim kulturom godności w tym zakresie stanowi kamuflowany lub nieuświadamiany akt adaptacyjnej kolonizacji terminologicznej. Antropolodzy starają się wykazać wprawdzie tubylczo stylizowaną, ale jednak obecność europejskich kategorii w kulturach dawniej pomawianych o ich brak. W efekcie, szanując nieeuropejskie konteksty życia społeczności pierwotnych, jednocześnie usilnie pragniemy awansować przedstawicieli tych kultur do rangi równoprawnych partnerów w dziedzinie właśnie europejskiego dyskursu estetycznego. Pomijając kwestię widocznego tu błędnego logicznie koła w tej ucieczce przed kategorialną „europeizacją” wytwórczości plemiennej, dodać wypada kolejną trudność. Otóż wraz z postmodernistyczną falą dekonstrukcji fundamentalnych pojęć filozoficznych nastąpił kryzys definiowania istoty sztuki. Okazało się, m.in. za sprawą słynnego i wpływowego artykułu Morrisa Weitza, że jest to pojęcie nieścisłe, nadmiernie rozległe treściowo lub po prostu trudne do ustalenia, merytorycznie niekonkluzywne. W sytuacji, gdy pojęcie sztuki traci swoje jednoznaczne odniesienie przedmiotowe, i to wobec dzieł tworzonych w Europie, to cóż sądzić o sztuce lub jej braku w kulturach pierwotnych niedywagujących nad teorią rodzimej wytwórczości (Bugaj, 2003)?

Alternatywą dla tak zarysowującego się dylematu miał być projekt sztuki jako doświadczenia wyrażony w filozofii pragmatyzmu. W szczególności neopragmatyści orędujący za przygodnością, tymczasowością niespójnych „struktur” pojęciowych położyli akcent na powszechną estetyzację życia. Prominentny przedstawiciel tego kierunku Richard Shusterman opowiada się za antyesencjalizmem w pojmowaniu sztuki. Nie jest ona wobec innych praktyk życiowych czymś wyróżnionym, nie przysługuje sztuce uniwersalne i ponadczasowe określenie. Jak pisał: „Sama forma narracji definiującej sztukę musi być otwarta oraz podatna na zmiany" (Shusterman, 1998, s. 81). Powołując się na poglądy Richarda Rorty'ego i Nelsona Goodmana, Shusterman tak dalece uzależnia sens sztuki od zmiennych kontekstów jej istnienia, że w rezultacie gotów byłby zaniechać wszelkich wysiłków zmierzających do ukazania jej obiektywnej, ponadhistorycznej istoty. Podobnie zapatruje się na aksjologię przeżyć estetycznych. Jego zdaniem modernistyczna ,racjonalizacja pozalogicznego wymiaru przeżycia estetycznego" wyprowadza poza zakres zainteresowań estetyki intensywne doświadczenia zarówno archaicznej Grecji, jak i ludów afrykańskich (Shusterman, 2005, s. 169, 155).

Pogląd o sztuce będącej niewyspecyfikowaną formą aktywności oraz o możliwej w kulturze pierwotnej postawie estetycznej znajdujemy w dziełach Johna Deweya, jednego z twórców pragmatyzmu. Warto najpierw przywołać jego ogólne uwagi na interesujący nas temat, a następnie przyjrzeć się podanej przez niego wizji sztuki w kulturze tubylców australijskich. W dalszej kolejności stwierdzenia Deweya zostaną uzupełnione uwagami Émila Durkheima dotyczącymi sztuki w kontekście austra- 
lijskiego totemizmu, jako że francuski socjolog korzystał z pierwszych opracowań etnograficznych na temat kultury aborygeńskiej.

Według Deweya na charakter sztuki w kulturach pierwotnych składają się następujące elementy i cechy:

1. Sztuka jest integralnym składnikiem doświadczenia życia, które jest udziałem każdego człowieka, a tym bardziej ludzi pierwotnych: „Nie musimy szukać aż na krańcach świata ani cofać się w czasie o całe tysiąclecia, aby znaleźć ludy, dla których wszystko, co wzmaga bezpośrednie odczuwanie życia, jest godne największego uznania" (Dewey, 1975, s. 9).

2. Składnik estetyczny wytwórców pochodzących z rozmaitych kręgów kulturowych, nawet po przeniesieniu w inne środowisko i po utracie „,czynników lokalnych", utrzymuje uniwersalną wartość tych obiektów (Dewey, 1975, s. 157).

3. Wytwory sztuki archaicznej przeniknięte są rytmem stanowiącym ich jakość formalną, wizualną, czynnościową, dlatego że same są ekspresją rytmów kształtujących doświadczenie życia ludzi pierwotnych: „Tajemnicze ruchy węża, łosia, dzika układały się w rytmy, które realizowały samą istotę życia tych zwierząt, kiedy przedstawiono je w tańcu, rzeźbiono w kamieniu, wykuwano w srebrze lub malowano na ścianach jaskiń (Dewey, 1975, s. 180).

4. Sztuka nie jest odtworzeniem lub ukazywaniem lecz przeobrażeniem natury: „Również u ludów pierwotnych zawodzenie wcześnie przybiera formy ceremonialne, nader „odległe” od pierwotnych przejawów bólu” (Dewey, 1975, s. 98).

5. Sztuka od zarania nie należy do potrzeb „wtórnych”, do zbytku i naddatku w stosunku do ,podstawowych” wymogów życia. W kulturach pierwotnych wytwarzanie dzieł może być nawet bardziej doniosłe dla życia niż troska o zabezpieczenie potrzeb elementarnych: „Przypuszczam, że fetysze, które wykonywał rzeźbiarz murzyński, były uważane za coś w najwyższym stopniu pożytecznego dla jego grupy plemiennej, nawet bardziej od dzid i odzieży" (Dewey, 1975, s. 34).

6. Praktyki życia ludów pierwotnych są źródłem późniejszych sztuk pięknych: „Każda wyprawa antropologiczna w przeszłość coraz wyraźniej pokazuje związki, jakie łączyły początek różnych dziedzin sztuki z pierwotnymi obrzędami rytualnymi (Dewey, 1975, s. 38); „Taniec i pantomima, które dały początek sztuce teatralnej, rozkwitały jako część obrzędów i uroczystości religijnych. Sztuka muzyczna rozwijała się bujnie dzięki szarpaniu naciągniętej struny, biciu w rozpiętą skórę i dęciu w fujarkę. Nawet w jaskiniach, gdzie mieszkali ludzie, ściany były ozdobione kolorowymi malowidłami, które ożywiały w pamięci zdarzenia związane ze zwierzętami, włączonymi przecież tak ściśle do życia człowieka" (Dewey, 1975, s. 10).

7. Folklor słowny nie pełnił funkcji poznawczych, nie stanowił werbalnie ujętej wizji świata, nie służył poszerzaniu plemiennej wiedzy, lecz sprzyjał doświadczeniom w pierwszym rzędzie estetycznym: „Mity nie miały nic wspólnego 
z intelektualizującą wyprawą człowieka pierwotnego w dziedzinę nauki. Niepewność w obliczu nieznanego odgrywała zapewne w nich niejaką rolę, ale dominowało zadowolenie z samej opowieści, z dobrej gawędy, ze sposobu rozwijania się narracji i z wykonania..." (Dewey, 1975, s. 38). Przywołując słowa antropologa Alexandra Goldenweisera, Dewey stwierdził, że supernaturalizm jest przeważającym wyobrażeniem u ludów pierwotnych, ponieważ „fantasmagoria supernaturalizmu jest estetycznie atrakcyjna” (Dewey, 1929, s. 81-82).

Spójrzmy teraz na interpretację sztuki odnotowanej wśród plemion australijskich, które w czasie, gdy Dewey pisał swoje rozważania na jej temat, uchodziły za ludy najstarsze historycznie i typologicznie. Według XIX-wiecznych antropologów kultura aborygeńska była skamieliną życia najdawniejszych naszych przodków i z tego powodu traktowano ją jako swoisty poligon dla badań nad pierwotnymi etapami życia ludzkości. W szkicu Interpretation of Savage Mind z 1902 roku Dewey zawarł istotne uwagi na temat charakteru i roli sztuki w życiu wspólnot zbieracko-łowieckich. Zacząć trzeba od tego, że Dewey rozpatruje życie ludzi pierwotnych pod kątem typowych dla nich zajęć. Zajęcia, a więc to, czym na co dzień trudni się człowiek pierwotny, zajmują całkowicie jego uwagę, budują całościowe nastawienie do świata, które wypełnione jest ,apercepcyjnymi masami”. Zajęcia zaś kształtują nawyki, te zaś rodzą szeregi skojarzeniowe i niejawne klasyfikacje wartościujące ludzkie życie (Dewey, 1902, s. 219-220). W psychice rolników posługujących się skomplikowanym zestawem narzędzi, zabiegów agrotechnicznych rozłożonych w czasie dochodzi do przerwy dzielącej początek zadania i jego realizację. Tymczasem w przypadku polowania, a więc w nastawieniu myśliwych, nie ma takiego pośrednictwa. Pierwotny myśliwy zwykle dąży do szybkiego zaspokojenia potrzeby, jaką jest upolowanie zwierzyny. Fakt ten tłumaczono nieudolnością pierwotnych łowców lub ich niechęcią do tworzenia „obiektów pośredniczących” (trwałych narzędzi, stałych siedzib itp.). Ale widoczna tu wstrzemięźliwość wobec takich innowacji dokładnie odpowiada zajęciom myśliwych i ich postawie doświadczeniowej. Polega na zatrzymywaniu uwagi i skutecznym wysiłku tylko na tych elementach ich zatrudnienia, które gwarantują wyrażanie się w sferze najlepiej przez nich opanowanej (Dewey, 1902, s. 223). Dlatego sztuka Aborygenów jest przede wszystkim choreograficzna, dramatyczna, odpowiednio przeobraża doświadczenia łowieckie, stroni od realistyczno-naturalistycznych przedstawień plastycznych. Jest to sztuka pełnego udziału w ekspresji przeżyć i eksponowania sytuacji związanych z polowaniami: podchodzeniem i wypatrywaniem zwierzyny, pościgiem, wytrwałością, cierpliwością, dokładnością, zmaganiem się itd. Wszystkie te rytualizowane ekspresje służą potęgowaniu autentycznych doświadczeń życiowych. Według Deweya w efekcie sztuka dynamizmu dramatycznego nie jest ilustracją przeżyć myśliwego, ale ich odpowiednim ułożeniem, a nade wszystko ich intensyfikacją (Dewey, 1902, s. 226). Z niejaką rezerwą, ale też akceptacją Dewey przywołuje tezę Carla Lumholtza, że niektóre ludy uprawiają myślistwo nie dla zdobycia pożywienia, lecz w celu wzbudzenia określonych emocji kształtujących postawy i życie łowców. Emocje te stwarzały taki rodzaj organicznego napięcia, że 
dawały uczucie estetycznej satysfakcji. W takim układzie samo polowanie byłoby formą sztuki, sztuki właśnie jako życia i doświadczenia (Dewey, 1902, s. 224).

Jak wiadomo, problematyce sztuki aborygeńskiej wiele uwagi poświęcił Émile Durkheim. Realizacje plastyczne, a przede wszystkim ich funkcję interpretował w kontekście rekonstruowanej religii totemicznej. W Australii wykonywano wizerunki istot będących godłami klanu, tzw. totemy. Przedmioty noszące takie plastyczne wyobrażenia charakteryzowały się, jak uważali tubylcy, obecnością mocy, szczególną świętością. Durkheim zwraca uwagę, że przedmioty zdobione, uosabiające moc totemu, były splecione z mitami na ich temat. Co jednak ciekawe, poszczególne przedstawienia nie odwzorowywały mitów, nie wynikały z mitycznych przesłanek, lecz odwrotnie. To respekt wzbudzany przez święte przedmioty był potem źródłem mitycznych opowieści o tych obiektach (Durkheim, 1990, s. 113).

Można wobec tego zauważyć, że wyobrażenia aborygeńskie nie były skonwencjonalizowanymi znakami, symbolami, zarówno narracji mitycznych, jak i naturalnych obiektów widzianych przez ludzi pierwotnych. O tej sztuce „bez symboli” pisał Durkheim:

Otrzymane w ten sposób figury są tak dowolne, że identyczny rysunek może mieć dwa różne znaczenia dla dwóch ludzi odmiennych totemów i wyobrażać raz takie, a kiedy indziej inne zwierzę lub roślinę [...]. Wynika z tego, że dwie nurtunje mogą mieć dokładnie taki sam wygląd, a mimo to wyrażać dwie tak różne rzeczy, jak drzewo gumowe i emu. (Durkheim, 1990, s. 117)

Podobnie wypowiadał się Dewey na temat nieobecności symbolu w sztuce ludów pierwotnych. Jego zdaniem w ikonicznych realizacjach nie jest ważne odniesienie wyobrażenia do jego pozaprzedmiotowego znaczenia, lecz bezpośrednie działaniowe celebrowanie samego obrazu (Dewey, 1929, s. 82). Widzimy tu zatem dominację tzw. związków wyrażania, zamiast związków znaczenia, o czym pisał Ernst Cassirer. Nie ma w tym niczego zaskakującego, jeśli przyjmiemy założenie, że sztuka istnieje w strumieniu życiowych doświadczeń, że ma wymiar praktyczny. Jakby na poparcie takiego poglądu, Durkheim stwierdził, że: „Wszelkiego rodzaju wizerunki przedstawiające totem otoczone są szacunkiem znacznie większym niż istota, której postać wyobrażają" (Durkheim, 1990, s. 124). Gdyby zatem wizerunki były prezentacjami symbolicznymi obiektów naturalnych (rzeczywistych zwierząt uważanych za totemowe), to sytuacja byłaby odwrotna. Można by powiedzieć, że Aborygeni byli pierwotnymi ikonofilami, ale $\mathrm{w}$ takim rozumieniu, że w ich doświadczeniu substancja obrazu była ontologicznie identyczna z substancją obiektu przedstawionego. Oglądanie obrazów nie miało na celu kontemplacji treści widzianego przedstawienia, lecz prowadziło do ożywienia odpowiednich nastrojów, następującego w poczuciu kontaktu z pełnym uobecnieniem tego, co oglądane.

W sytuacji, gdy sztuka pierwotna nie pełni funkcji semiotycznych lub kognitywnych we współczesnym rozumieniu, nie można oceniać jej twórców i konsumentów pod względem złożoności układów poznawczych. Inaczej mówiąc, sama obecność 
dzieł plastycznych nie świadczy o poziomie rozwoju duchowego. Rodzaj doświadczeń życiowych, typowych dla ludów myśliwskich, komentowany był z jednej strony jako określony estetycznie, a z drugiej pozbawiony kognitywnych alternatyw, takich, jakimi legitymują się ludzie nowocześni. Prowadzi to do zdumiewających, czasem kontrowersyjnych, ale interesujących spostrzeżeń. Do takich należą słowa spisane przez Erazma Majewskiego, dla którego, co warto podkreślić, punktem wyjścia oceny artyzmu sztuki pradziejowej były tezy bardzo zbliżone do pragmatyzmu Deweya. Pisał następująco:

Dla nas rzekomo wysoki artyzm jaskiniowców świadczy zupełnie o czem innem, mianowicie o ogromnej prymitywności ich dusz. Majewski wykazuje, że inteligencja i wysiłek uczuciowy łowców skupione były na praktycznych zadaniach, jakie musi wykonać drapieżne zwierzę. Coś podobnego zachodzi i z bardzo pierwotnym synem puszczy, którego głównem zajęciem jest podchodzenie i ściganie zwierzyny, a także unikanie i tępienie niebezpiecznych współmieszkańców tego samego obszaru [...]. W myślach też jego i wspomnieniach przewijają się najczęściej i najżywiej obrazy zwierząt i to niezmiernie wyraziste... [...]. Nie porównywajmy też „myśliwskiej” wyobraźni jaskiniowca z wyobraźnią oraz widnokręgiem myśli i marzeń choćby najbardziej zapalonego Nemroda naszych czasów. Myśl ostatniego, gdy tylko odłoży sztucer, ślizga się po tysiącu tematów, dalekich od polowania [...] Naszemu Nemrodowi zaciera żywość wyobrażeń myśliwskich cała cywilizacja, ów bezmiar abstrakcji, który nas spowija i daje szerokość oraz głębię poznania, tamtemu zaś, jak w czystem zwierciadle, rysuje się z cała przepyszna plastyka tylko to, dookoła czego uparta myśl ustawicznie się obraca. [...] Dla mnie ta właśnie nadzwyczajna trafność rysunku zwierząt i brak wszelkich innych tematów świadczy pośrednio, ale niezbicie o ogromnej jednostronności myśli magdaleńczyków [...]. (Majewski, 1923, s. 161-163)

Nie wnikając tu w dalsze rozróżnienia i analizy tych zjawisk, wystarczy powiedzieć, że według Deweya dawne wyobrażenia plastyczne mają walor estetyczny, ponieważ są istotnymi rekwizytami stosowanymi do wywołania określonych uczuć w ramach szerszego kompleksu doświadczeń i nawyków typowych dla plemion myśliwskich. Według Durkheima wizerunek w pierwszej kolejności służy uobecnieniu totemu i jego mocy, a dopiero w dalszej może (lecz nie jest to warunek konieczny) odnawiać uczucia mające zabarwienie estetyczne (Durkheim, 1990, s. 117-118). Nie zmienia to faktu, że w ocenie realizacji plastycznych Aborygenów u obu autorów najważniejszym kryterium jest asymboliczna funkcja bezpośredniego postrzegania przez podmioty własności konkretnego wizerunku. Chodzi o to, że to, co dla badacza jest wyobrażeniem wypełnionym treścią symboliczną, dla tubylca jest przedmiotem postrzeganym. Funkcja ta jest podporządkowana zadaniom wykorzystywania tych dzieł $\mathrm{w}$ trakcie określonych obrzędów. Mamy do czynienia z pragmatycznym modelem interpretacji roli sztuki jako użytecznego i efektywnego akcesorium ,wzmacniania poczucia życia" w grupach pierwotnych (Berndt, 1958, s. 105). W przypadku Deweya do głosu dochodzi stanowisko emocjonalizmu w kwestiach ekspresji estetycznej, natomiast u Durkheima skłonność do socjoorganizacyjnej oraz do słabiej ujawnionej, 
jakby wtórnej, ale także poznawczej (klasyfikacje totemiczne) funkcji sztuki pierwotnej.

Nie ulega zatem wątpliwości, że wytwórczość zaspokająca całokształt potrzeb życiowych jest w kulturach pierwotnych włączana w bieg doświadczeń grupowych. Wartości artystyczne wykorzystywanych przedmiotów mogą być wysokie, lecz według pragmatystów kunszt jest wtórny, a nawet mało ważny wobec roli, jaką obiekty te odgrywają w potęgowaniu doznań estetycznych. Przedmiot nie musi być wykwintny, rzadki ani piękny, żeby potrzebę takich doznań zaspokoić. Wypada zgodzić się z Edith Wysochrod, która, zestawiając koncepcję bricolage'u Clauda Lévi-Straussa z opisaną przez Deweya funkcjonalnością rytualnie wpisanych w umysł nawyków, dostrzega u obu pewną kategorię w ontologii pierwotnego bycia i doświadczenia świata (Wyschogrod, 1981). Z kolei Thomas D. Fallace zauważa wyraźne związki między Deweya wizją myślenia pierwotnego a jego programem pedagogicznym polegającym na odpowiednim kształtowaniu nawyków prowadzących do asymilacji życiowo istotnych wartości (Fallace, 2008).

$\mathrm{W}$ takiej sytuacji nie dysponujemy neutralnym kryterium opisu czy oceny sztuki i przeżyć estetycznych w kulturach pierwotnych, ponieważ realizacja takiego zabiegu musiałaby z konieczności relacjonować całokształt doświadczeń tych społeczności. Jest to trudność wynikająca głównie z ontologicznego układu tej synkretycznej (niepodzielnej) kultury, a to sprawia, że pozostające do dyspozycji sposoby jej interpretacji są poznawczo niezadowalające. Stąd też biorą się podniesione tu dwuznaczne konsekwencje w ocenie roli i znaczenia sztuki pierwotnej - jest artystycznie bogata, rodzi estetyczne przeżycia, a zarazem nie operuje symbolem, wskazuje na ograniczony potencjał kognitywny. Wydaje się, że pragmatyzm optujący za nobilitacją sztuk nieprofesjonalnych albo nieelitarnych nie przezwycięża ukazanych tu trudności.

\section{BIBLIOGRAFIA}

Berndt, R. M.

1958 Some Methodological Considerations in the Study of Australian Aboriginal Art. Oceania, 29(1), 99-126.

Bugaj, E.

2003 Problemy interpretacji zjawisk sztuki w archeologii w kontekście nieoczywistości sztuki. W: B. Gediga, A. P. Kowalski (red.), Estetyka w archeologii (s. 11-20). Gdańsk: Muzeum Archeologiczne w Gdańsku.

Dewey, J.

1902

1929

1975

Durkheim, E. 1990 Elementarne formy życia religijnego. System totemiczny w Australii. Warszawa: PWN.

Fallace, Th. D.

2008 John Dewey and the Savage Mind. Uniting Anthropological, Psychological, and Pedagogical Thought, 1894-1902. Journal of the Behavioral Sciences, 44(8), 335-349. 
Errington, S.

1994 What Became Authentic Primitive Art? Cultural Anthropology, 9(2), 201-226.

Lewis, P. H.

1961 A Definition of Primitive Art. Fieldiana Anthropology, 36(10), 221-241.

Majewski, E.

1923 Nauka o cywilizacji, t. 4: Narodziny i rozwój ducha na ziemi. Warszawa: Gebethner i Wolff.

Morphy, H.

1996 Aboriginal Art in a Global Context. W: D. Miller (red.), Worlds Apart. Modernity through the Prism of the Local (s. 211-239). London: Routledge.

Płonka, T.

2012 Kultura symboliczna społeczeństw zbieracko-lowieckich środkowej Europy u schytku paleolitu. Wrocław: Wydawnictwo Uniwersytetu Wrocławskiego.

Schneider, H. K.

1971 The Interpretation of Pakot Visual Art. W: G. F. Jopling (red.), Art and Aesthetics in Prim-

Shusterman, R. itive Society. A Critical Anthology (s. 55-63). New York: Dutton.

1998 Estetyka pragmatyczna. Żywe piękno i refleksja nad sztuka. Wrocław: Aureus.

2005 Praktyki filozofi, filozofia praktyki. Pragmatyzm a życie filozoficzne. Kraków: Universitas.

Torgovnick, M.

1989 Making Primitive Art Hight Art. Poetics Today, 10(2), 299-328.

Wyschogrod, E.

1981 The Logic of Artifactual Existents: John Dewey and Claude Lévi-Strauss. Man and World, 14(3), 235-250.

Żelazny, M.

1994 Źródlowy sens pojęcia estetyka. Rozprawy z historii estetyki niemieckiej. Toruń: Wydawnictwo Uniwersytetu Mikołaja Kopernika.

\section{THE MANUFACTURE OF THE PRIMORDIAL TRIBES IN THE CASE OF PRAGMATIC CONCEPTS OF THE ART}

\section{Sum mary}

For many years, the modern concept of art as the autonomic sphere has been negated by the researchers of the art in primordial societies. We cannot avoid some paradoxes because of the stereotypes of the gauche and noble overlap. If the art is to be aesthetic, then why the deeply sensual primordial societies were deprived of the idea of beauty? The other contradiction is visible in the rehabilitative strategies of the decolonization discourses. The Eurocentric classifications deprived the primordial tribes of art; thus, the mistake had to be fixed. Therefore, in the anthropology, the researchers concentrated on the idea of compensating the negative connotations. It was made by neopragmatism, mostly R. Shusterman. Giving back the dignity to other than European cultures is, in a sense, the adaptive terminological colonization. The anthropologists try to present the tribally stylized presence of the European categories in the primordial cultures. As a result, respecting non-European contexts of the primordial societies' lives, they want to elevate the representatives of these cultures to the rank of equal partners in the domain of the European aesthetic discourse.

The pragmatic vision of art proposed by J. Dewey presents its meaning in the whole life experience. Australian Aborigines, described by this philosopher, created artistically valuable tools. 
Mostly they danced, sang, and took part in the mimetic rituals. There were the arts of movement and dynamism harmonized with the rhythms of the hunter's actions. Art was a medium to intensify the postures and feeling accompanying huntings. The iconic realizations were of lesser importance. They did not promote symbolic thinking, only the magical one. The deep aesthetic satisfaction did not follow the development of the cognitive posture. The art helped the tribes to systematize their social customs and habits thanks to their aesthetic experience. The pragmatic proposition pushes the aesthetic feature of art to the first place. However, it does not rethink the cognitive functions of it. This fact hinders the work of archaeologists who look for the early signs of thinking and conventions rising from abstraction and symbolism. 